\title{
Lumbar spondylosis and neuropathic bladder: investigation of 73 patients with chronic urinary symptoms
}

\author{
M M SHARR, J S GARFIELD, J D JENKINS
}

British Medical fournal, 1976, 1, 695-697

\begin{abstract}
Summary
Seventy-three patients presented with either chronic urinary symptoms such as incontinence, retention, and recurrent urinary infection or chronic low back pain and neurogenic claudication. Lumbar spondylosis was considered to be the major cause of the urological and skeletal symptoms; the diagnosis of a neuropathic bladder depended as much on features in the history as on the results of urological and neurological investigations. The preoperative demonstration of significant lumbar spondylosis was often difficult, but decompressive laminectomy in 34 patients produced relief of urinary symptoms and improvement in bladder function in $\mathbf{7 5} \%$ •
\end{abstract}

\section{Introduction}

Clinicians are often faced with the problem of managing patients with intractable urinary symptoms, such as incontinence, which do not appear to be due to demonstrable lesions of the urinary tract. When neural control of the bladder and urethra fails the term neuropathic bladder is used. Some overt neurological disorders such as disseminated sclerosis and central prolapsed

\footnotetext{
Wessex Neurological Centre, Southampton General Hospital, Southampton SO9 4XY

M M SHARR, MRCP, FRCS, senior registrar in neurosurgery

J S GARFIELD, MRCP, FRCS, consultant neurosurgeon

Department of Urology, Southampton General Hospital SO9 4XY J D JENKINS, MCHIR, FRCS, consultant urological surgeon
}

lumbar intervertebral disc are well recognised, and usually easily diagnosed, causes of neuropathic bladder, while spinal tumour-although usually causing overt neurological deficit in addition to a neuropathic bladder-may present urologically rather than neurologically. ${ }^{1}$ A less well-known cause of neuropathic bladder is lumbar spondylosis, ${ }^{2}$ and because definite abnormal neurological signs are often absent the diagnosis may remain obscure for many years. We report here details of 73 patients with urinary symptoms in whom assessment and investigation indicated, in at least half, previously unrecognised appreciable spinal disease.

\section{Patients and findings}

Of the 73 patients 41 were women ranging in age from 21 to 73 years (average 55); ages in the 32 men ranged from 31 to 81 years (average 54). Fifty-two patients ( 26 women and $26 \mathrm{men}$ ) presented first to the urologist, and 21 patients ( 15 women and six men) presented first to the neurosurgeon. All patients were managed jointly by the urological and neurosurgical departments.

Urological presentation-The urological symptoms fell into three main groups-true incontinence; retention; and the symptoms of urinary tract infection, with bouts of dysuria, urgency, and frequency (table I). When present, infection was usually associated with an appreciable amount of residual urine. In some cases the presence of a urinary tract infection had not been confirmed bacteriologically before urological investigation. Incontinence was usually uncontrollable dribbling or total flooding. Some patients presented with overflow incontinence secondary to retention while others presented with a complex mixture of all three groups of symptoms; the predominant or most distressing symptom was used to place the patient in the appropriate category. Intermittency of symptoms was a feature, particularly in the women, and may have accounted for the length of time that some of these patients had tolerated their symptoms (see Discussion).

Neurological and skeletal presentation-The neurological or skeletal symptoms and signs were usually chronic low back pain (persisting for more than 30 years in some patients) with or without neurogenic 
TABLE I-Presenting symptoms and signs in 73 patients

\begin{tabular}{|c|c|c|c|c|c|c|c|}
\hline & Incontinence & Retention & $\begin{array}{l}\text { Urinary tract } \\
\text { infection }\end{array}$ & Backache & $\begin{array}{l}\text { Neurogenic } \\
\text { claudication }\end{array}$ & $\begin{array}{l}\text { Significant leg } \\
\text { weakness }\end{array}$ & $\begin{array}{l}\text { Saddle sensory } \\
\text { loss }\end{array}$ \\
\hline $\begin{array}{l}\text { Men } \\
\text { Women }\end{array}$ & $\begin{array}{l}16 \\
23\end{array}$ & $\begin{array}{r}13 \\
9\end{array}$ & $\begin{array}{l}3 \\
9\end{array}$ & $\begin{array}{l}24 \\
35\end{array}$ & $\begin{array}{l}16 \\
22\end{array}$ & $\begin{array}{l}4 \\
3\end{array}$ & $\begin{array}{l}4 \\
2\end{array}$ \\
\hline
\end{tabular}

claudication (table I). The criteria for the diagnosis of neurogenic claudication included sensory symptoms of a neurological distribution or weakness in the legs precipitated by exertion and relieved by rest. Nine patients had neither backache nor neurogenic claudication and only 10 had significant neurological deficit. A significant neurological deficit included considerable leg weakness, with or without reflex change, or definite saddle and perineal sensory loss.

Urological investigations included serum biochemical analyses, urine analysis, intravenous pyelography (IVP), cystoscopy, and cystometry. The appearance of the lumbar spine was noted on the IVP. The IVP showed a large residual urine in nine patients. The micturating cystogram, done in 30 patients, showed some abnormality of the bladder neck in four patients and a large irregular bladder in seven patients. Cystometry (by the simple technique of filling the bladder with normal saline via a urethral catheter and then measuring the pressure by a three-way tap system and a manometer) showed two main abnormal patterns-namely, the atonic (lower motor neurone) and the uninhibited or hypertonic (upper motor neurone) (fig 1). Since the cystometrographic method was simple and did not include rectal subtraction, results were accepted as abnormal only when unequivocal (table II).

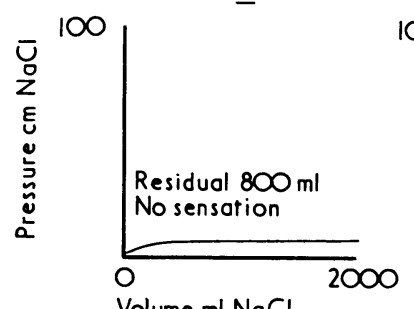

ume $\mathrm{ml} \mathrm{NaC}$

Cystometrographic patterns: (A) atonic (lower motor neurone); (B) uninhibited (hypertonic or upper motor neurone).

TABLE II-Cystometrographic patterns in 73 patients

\begin{tabular}{l|c|c|c|c|c}
\hline & Atonic & Uninhibited & Equivocal & Normal & $\begin{array}{c}\text { No } \\
\text { cystometry }\end{array}$ \\
\cline { 1 - 3 } Wen & 8 & 1 & 6 & 9 & 8 \\
Women & 5 & 7 & 8 & 17 & 4 \\
\hline
\end{tabular}

Neurological investigation-The plain radiographs of the lumbar spine were examined not only for the usual spondylotic changes but also for narrowing of the bony canal in the saggital plane and for disparity in the distance between the superior facets and the pedicles. Myelography, done in 59 patients, using iophendylate (Myodil) or a water-soluble contrast medium meglumine iothalamate (Conray 280) showed complete obstruction in 10 patients and narrowing or indentation of the contrast column in 25 . In 24 patients the appearances were either normal or equivocal (see Discussion).

Surgery-The indications for surgery were the presence of a neuropathic bladder with or without other neurological symptoms or deficit and radiological evidence of lumbar spondylosis. The operation consisted of a wide decompressive laminectomy with removal of ligamenta flava and, when necessary, the medial facets of the hypertrophied interlaminar joints. The operative findings included hypertrophied posterior interlaminar joints, thickened ligamenta flava, and thick sclerotic laminar bone, often with a poor correlation between the degree of narrowing shown myelographically and that found at operation. Only two patients had a combination of spondylosis and a significant prolapsed intervertebral disc. Of the 34 patients who underwent operation 22 presented to the urologist and 12 to the neurologist or neurosurgeon. Follow-up was complete in an average of three years, five years being the longest period of follow-up. An "excellent" result indicated a return to normal bladder function; "good" a definite improvement; and "poor" no improvement (table III). Neurological or skeletal symptoms refer to back pain and neurogenic claudication. Twenty-six patients $(77 \%)$ benefited urologically and $23(68 \%)$ benefited from the neurological or skeletal aspect. All patients with abnormal preoperative findings on cystometry who benefited from surgery showed either a normal cystometrographic pattern or a considerable improvement after operation.

TABLE III-Results of decompressive laminectomy in 34 patients

\begin{tabular}{l|c|c|c} 
& Excellent & Good & Poor \\
\hline $\begin{array}{l}\text { Urological } \\
\text { Neurological or skeletal }\end{array}$ & $\begin{array}{c}21(62 \%) \\
16(47 \%)\end{array}$ & $\begin{array}{c}5(15 \%) \\
7(21 \%)\end{array}$ & $\begin{array}{r}8(23 \%) \\
11(32 \%)\end{array}$
\end{tabular}

\section{Discussion}

\section{UROLOGICAL PRESENTATION}

The essential demonstration of a neuropathic bladder demands careful assessment of urological and neurological symptoms and the exclusion of a lesion in the urinary tract and requires, therefore, a combined urological and neurosurgical approach. The occurrence of urological symptoms in patients with prolapsed lumbar intervertebral discs has been emphasised, ${ }^{3}$ but incontinence without overflow was not described. Incontinence was one of the commonest problems, being the major urological symptom in 39 of our 73 patients. Incontinence in men is usually due to prostatic obstruction, with a large residual urine and an atonic bladder-so-called "retention with overflow" -but otherwise it is rare and may well indicate a neuropathic bladder. Failure to appreciate this led to prostatectomy in three patients who subsequently came to laminectomy. Gynaecological and urethral lesions make the assessment of incontinence in women considerably more difficult. ${ }^{4}$ The clinical diagnosis of neuropathic incontinence depends particularly on the patient's unawareness of bladder filling, emptying, and urethral flow. ${ }^{5}$ Diagnosis was more difficult in some of our women patients because incontinence was intermittent and precipitated or aggravated by exercise and even posture. When related to exercise the patients often had neurogenic claudication, and the higher incidence of claudication in women (table I) suggests that intermittent incontinence is due to similar ischaemia. Many women had tolerated uncomplainingly their socially distressing symptoms for many years. Thus women who have incontinence or incomplete bladder emptying without urinary infection, a demonstrable urinary tract lesion, or prolapse should be assumed to have a neuropathic bladder. ${ }^{6}$ as should those of either sex who develop retention without a urinary tract lesion or pelvic disease.

\section{UROLOGICAL INVESTIGATION}

Urine analysis, urography, and cystoscopy are necessary to exclude structural lesions of the urinary tract before diagnosing a neuropathic bladder. Our method of cystometry was simple and may be criticised on the grounds that rectal pressures and urethral pressure flow measurements, as used by other workers, ${ }^{7}$ were not assessed. Although considerable emphasis has been placed on the value of cystometry in the diagnosis of neuropathic 
bladder, ${ }^{8}$ like others,${ }^{3}$ we have found its value limited. Only 21 of our 73 patients had an unequivocally abnormal cystometrogram, most of these being of the expected atonic or lower motor neurone pattern; in eight patients, however, the pattern was of the uninhibited or upper motor neurone type-a surprising finding, which, nevertheless, has been reported in patients with prolapsed lumbar intervertebral disc. ${ }^{9}$ Such a "cord" pattern may be due to an ischaemic disturbance of the conus medullaris caused by compression of the ascending radicular arteries either by a prolapsed lumbar intervertebral disc or lumbar spondylosis. Cystography was rarely helpful and had only a limited part to play.

\section{DIAGNOSIS OF LUMBAR SPONDYLOSIS}

The pathological features of lumbar spondylosis include dense sclerotic bone, enlarged posterior interlaminar joints, and thickened ligamenta flava, the pre-existing saggital diameter of the bony canal being an important additional factor. These changes may constrict the cauda equina and individual nerve roots with the accompanying radicular arteries at the intervertebral foramina.

It may be difficult to differentiate between lumbar spondylosis and prolapsed lumbar intervertebral disc because the symptoms are often similar, and although the term "lumbar disc syndrome" has been used to encompass both conditions, ${ }^{10}$ Teng and Papatheodorou ${ }^{11}$ described distinguishing features, emphasising the significance of severe long-standing backache in lumbar spondylosis. In cases of prolapsed lumbar intervertebral disc the absence of appreciable neurological deficit, especially saddle sensory loss, may be common and therefore of no great diagnostic value, ${ }^{3}$ and, although tho et al ${ }^{12}$ reported a high incidence of saddle sensory loss in their patients with prolapsed lumbar intervertebral disc, they reported three patients with a neuropathic bladder and only L 5-S 1 sensory loss. The disparity between symptoms and signs in lumbar spondylosis was reported by Wilson et $a l_{, 13}$ and this feature is valuable in distinguishing it from prolapsed intervertebral disc. Fifty-nine $(81 \%)$ of our patients gave a history of backache for up to 30 years or more. Twenty-two $(65 \%)$ of the patients operated on had neurogenic claudication, 15 being women, while only 10 had significant neurological deficit.

The features of lumbar spondylosis may be obvious on the plain radiographs, with actual narrowing of the bony canal in the saggital plane, sclerosis of the posterior interlaminar joints, and disparity in distance between pedicles and articular facets. ${ }^{14}$ Recent studies have shown the superiority of water-soluble contrast (as opposed to oil contrast) because it delineates the posterior and anterior configuration of the theca simultaneously, although the examination is restricted to below the level of the spinal cord because of the adverse effects of the contrast medium on the cord. When oily contrast is used, screening in the supine position is essential because the final indication for surgery may depend on the configuration of the posterior aspect of the theca.

\section{SURGERY}

The 34 patients who underwent operation were those with the most severe symptoms, including some who were facing the prospect of urinary diversion, and they cannot be compared with the other 39 patients with milder symptoms. A poor general condition precluded surgery in four patients.

Since the first patient was treated in 1970 our interpretation of the myelographic findings has become more critical. At first, when oily contrast was used, lumbar spondylosis was diagnosed only in the presence of obvious constriction of the iophendylate column. As the limitations of this method of examination were recognised, however, and with the introduction of water-soluble contrast, we paid greater attention to relatively minor irregularities of the posterior aspect of the theca in the absence of obvious constriction-changes that are generally acceptable in a normal myelogram. Thus six patients with "normal" mylograms were treated surgically because they fulfilled other diagnostic criteria, and, indeed, they were found at operation to have significant lumbar spondylosis. Other patients with normal myelograms were managed conservatively either because the diagnosis of neuropathic bladder was in doubt or because symptoms were not distressing. With the change in interpretation of myelography, however, some of the earlier patients managed conservatively would probably now be considered for surgery.

The importance of adequate decompression, both bony and ligamentous, and the dangers of removal of a small disc prolapse only have been emphasised. ${ }^{15}$ In assessing the results of surgery a comparison with other series would have been of interest, but otherwise comprehensive accounts of patients with lumbar spondylosis ${ }^{10}{ }^{13}$ lack details of associated bladder dysfunction.

The encouraging results of surgery for the relief of urinary symptoms in our earlier report ${ }^{2}$ were maintained in this series (table III). Postoperatively normal bladder function recovered in patients whose symptoms, often severe, had been present for many years and whose preoperative cystometrograms were abnormal. It has been said that true recovery of bladder function requires cystometrographic confirmation, ${ }^{12}$ and all but three of our 13 patients with abnormal preoperative cystometrograms showed striking cystometrographic and clinical improvement after surgery. Nevertheless 21 patients had normal preoperative cystometrograms, and 15 of these showed clinical improvement after surgery. Saddle sensory loss is an adverse factor ${ }^{16}$ and of six such patients only two improved. Surgery for the skeletal and neurological symptoms has been less encouraging, 11 of the 34 patients being no better. There are still 39 patients who have not been operated on because of age, lack of clear diagnosis, lack of evidence of progressive symptoms, and improvement in some by simple conservative measures such as bed rest, corset, etc, and these patients are being kept under review.

\section{References}

1 Garfield, J, and Lytle, S, N, British Fournal of Urology, 1970, 42, 551. 2 Sharr, M M, Garfield, J S, and Jenkins, J D, British Fournal of Urology, $1973,45,616$.

3 Emmett, J L, and Love, J G, fournal of Urology, 1971, 105, 86.

4 Edwards, L E, Annals of the Royal College of Surgeons of England, 1973, 52, 69.

5 Sharr, M M, fournal of Neurology, Neurosurgery and Psychiatry, 1973, 36, 888 .

6 Ross, J C, and Jameson, R M, British Medical fournal, 1971, 3, 752.

7 Bates, C P, Annals of the Royal College of Surgeons of England, 1971, 49, 18.

${ }^{8}$ Rosomoff, H L, et al, fournal of Neurosurgery, 1970, 33, 67.

9 Jones, D L, and Moore, T, British fournal of Urology, 1973, 45, 39.

10 Paine, K, and Haung, P W, Fournal of Neurosurgery, 1972, 37, 75.'

11 Teng, P, and Papatheodorou, C, Archives of Neurology, 1963, 8, 221.

12 Aho, A J, Auranen, A, and Pesonen, K, Acta Chirurgica Scandinavica, 1969, 135, 413.

${ }^{13}$ Wilson, C B, Ehni, G, and Grollmus, J M, Clinical Neurosurgery, vol 18, p 62. Baltimore, Williams and Wilkins, 1971.

14 Roberts, G, personal communication.

15 Ehni, G, Texas State fournal of Medicine, 1965, 61, 746.

${ }_{16}$ Scott, P J, fournal of Bone and foint Surgery, 1965, 47B, 224.

\section{What are the hazards of men working with tar machines?}

Presumably this refers to those fascinating but terrifying machines which belch forth fire, black smoke, and tar while constructing and repairing roads. Epidemiological evidence indicates that men exposed to pitch and tar are at much increased risk of developing skin cancers, particularly of the scrotum, and at slightly increased risk of developing cancers of the lung and urinary bladder. Less is known about the risks to road workers than to men in other occupations which necessitate exposure to tar because itinerant and casual labour is much used by road-building contractors. Possibly, however, the risks for road workers are reduced because the fumes are quickly dispersed in the open air. 